\title{
Original
}

\section{Adipsia increases risk of death in patients with central diabetes insipidus}

\author{
Hiroshi Arima ${ }^{1)}$, Toshihiko Wakabayashi' ${ }^{2)}$, Tetsuya Nagatani ${ }^{2)}$, Masazumi Fujii' ${ }^{2)}$, Akihiro Hirakawa ${ }^{3)}$, \\ Takashi Murase ${ }^{4)}$, Yuko Yambe ${ }^{4)}$, Tsutomu Yamada ${ }^{4)}$, Fumiko Yamakawa ${ }^{4)}$, Ikuo Yamamori ${ }^{5)}$, \\ Masako Yamauchi ${ }^{5)}$ and Yutaka Oiso ${ }^{1)}$ \\ 1) Department of Endocrinology and Diabetes, Field of Internal Medicine, Nagoya University Graduate School of Medicine, \\ Nagoya 466-8550, Japan \\ 2) Department of Neurosurgery, Nagoya University Graduate School of Medicine, Nagoya 466-8550, Japan \\ 3) Biostatistics Section, Center for Advanced Medicine and Clinical Research, Nagoya University Graduate School of Medicine, \\ Nagoya 466-8550, Japan \\ 4) Department of Endocrinology and Diabetes, National Hospital Organization Nagoya Medical Center, Nagoya 460-0001, Japan \\ 5) Department of Endocrinology and Metabolism, Japanese Red Cross Nagoya Daiichi Hospital, Nagoya 453-8511, Japan
}

\begin{abstract}
Central diabetes insipidus (CDI) is caused by deficiency of arginine vasopressin, an antidiuretic hormone. Patients with CDI manifest polyuria which is usually compensated for by increases in water intake. However, some patients are not able to sense thirst due to the destruction of osmoreceptors in the hypothalamus. These adipsic CDI patients are easily dehydrated and the consequent dehydration could be life-threatening. The objective of this study was to investigate the prognosis of adipsic CDI patients. We have reviewed 149 patients with CDI in three hospitals using databases of the electronic medical recording systems, and examined whether adipsia could affect the morbidity and mortality in CDI patients with multivariable analyses. Twenty-three patients with CDI were adipsic while the remaining 126 patients were non-adipsic. The multivariate analyses showed that the incidence of serious infections which required hospitalization was significantly higher in the adipsic CDI patients compared to that in non-adipsic CDI patients $(p<0.001)$. A total of 6 patients with CDI died during the follow-up (median duration; 60 months, range 1 to 132 months). Four of them were adipsic, three of whom died of infection. The statistical analyses revealed that the risk of death in adipsic CDI patients was significantly higher than in non-adipsic patients $(p=0.007)$. It is thus suggested that adipsic CDI patients were susceptible to serious infections which could be the causes of death.
\end{abstract}

Key words: Vasopressin, Adipsia, Hypernatremia, Prognosis, Infection

\begin{abstract}
ARGININE VASOPRESSIN (AVP) is an antidiuretic hormone which is synthesized in the supraoptic and paraventricular nuclei in the hypothalamus, and released into the systemic circulation from the posterior pituitary [1,2]. Secretion of AVP is precisely controlled by plasma osmolality so that even as little as $1 \%$ increases in plasma osmolality or serum sodium levels significantly increase plasma AVP levels [1, 2]. Increases in plasma osmolality are sensed via the osmoreceptors in the hypothalamus, and induce not

Submitted Sep. 6, 2013; Accepted Oct. 22, 2013 as EJ13-0368 Released online in J-STAGE as advance publication Nov. 9, 2013 Correspondence to: Hiroshi Arima, Department of Endocrinology and Diabetes, Field of Internal Medicine, Nagoya University Graduate School of Medicine, 65 Tsurumai-cho, Showa-ku, Nagoya 466-8550, Japan. E-mail: arima105@med.nagoya-u.ac.jp
\end{abstract}

only AVP release but also thirst sensation and water intake $[1,2]$. In contrast to the small changes in plasma osmolality required for AVP release, 2-3\% increases in plasma osmolality are necessary to induce thirst sensation [3]. As changes in plasma osmolality are within $1-2 \%$ of the basal level under most conditions due to the antidiuretic action of AVP, these small changes are below the threshold of thirst [2].

Central diabetes insipidus (CDI) is caused by deficiency of AVP, and the etiologies include several diseases in the hypothalamus such as germ cell tumor of the central nervous system, craniopharyngioma and inflammatory diseases [4-6]. Patients with CDI manifest polyuria, which is compensated for by increases in water intake if thirst sensation is intact. However, some patients are adipsic, because not only AVP neurons 
but also the osmoreceptors in the hypothalamus are destroyed, and easily become dehydrated unless properly treated $[7,8]$. Such dehydration caused by deficits in both AVP release and thirst sensation could be life-threatening [9]. Indeed, hypernatremia is reportedly associated with high mortality in hospitalized patients [10], and the mortality rate in hypernatremic patients further increased when they had bacterial infection [11]. Adipsic CDI patients could also have thromboembolism [9], and some patients reportedly died of respiratory failure at relatively young ages [9].

In the present study, we reviewed 149 CDI patients in three hospitals, and investigated whether adipsia could affect the morbidity and mortality in patients with CDI.

\section{Materials and Methods}

\section{Patients}

Using databases of the electronic medical recording systems, 170 patients (96 males and 74 females) with CDI were reviewed in March 2013 in the Nagoya University Hospital, the National Hospital Organization Nagoya Medical Center and the Japanese Red Cross Nagoya Daiichi Hospital. These three hospitals have endocrinology, pediatrics and neurosurgery departments, and the protocol of study was approved by the institutional review board of each hospital. Four patients were excluded from the study of prognosis because the onset of CDI was not clear, and 12 were excluded as they died of the original diseases that possibly caused CDI ( 9 of cancer, 2 of germ cell tumor of the central nervous system, and 1 of hemorrhage from the pituitary tumor after surgery). Four patients in whom CDI was caused by cardiac arrest and resultant cerebral hypoxia were also excluded as they did not recover fully and died of heart failure or infection within two years (1 to 21 months). As a result, a total of 149 patients were subjected to the analysis of prognosis. The median age at diagnosis of CDI was 36 years (range, 0 to 78 years). The median duration of follow-up was 60 months (range, 1 to 132 months).

\section{Diagnosis of CDI and adipsia}

The diagnosis of CDI was based on a history of polyuria and polydipsia that had been controlled by desmopressin (DDAVP). In addition, pituitary MRI was examined in 144 patients, and the bright spot in the posterior pituitary on midsagittal T1-weighted MRI of the brain was absent in all of them. In the remaining 5 patients, a deficiency in plasma AVP responses to osmotic stimulation with hypertonic saline was confirmed in 1 patient, and the onset of polyuria was close to the time when the original diseases were diagnosed (2 patients) or just after pituitary surgery ( 2 patient). Adipsia could be diagnosed by low thirst response to plasma hypertonicity during hypertonic saline injection [7]. In this retrospective study, adipsia was diagnosed based on medical records indicating that patients did not sense thirst even when the serum sodium levels were $\geq 150$ $\mathrm{mmol} / \mathrm{L}$. As CDI patients were screened based on the history of prescription of DDAVP, adipsic patients who did not require treatment of DDAVP were not involved in the current investigation.

\section{Anterior pituitary function}

The substitution of hormones including steroid hormone, thyroid hormone, $\mathrm{GH}$ and gonadal hormone was investigated on the medical records. The diagnosis of anterior pituitary dysfunction was based on the basal levels of plasma anterior pituitary hormones or the responses of ACTH, GH, TSH/PRL and LH/FSH to $\mathrm{CRH}, \mathrm{GRH}, \mathrm{TRH}$ and $\mathrm{GnRH}$, respectively.

\section{Morbidity and mortality}

The incidence of serious infections, which required hospitalization, thromboembolism, respiratory failure and death was investigated in 23 adipsic and 126 nonadipsic CDI patients.

\section{Serum sodium levels}

In the 149 patients subjected to the analysis of prognosis, all the data of serum sodium levels were reviewed, and the incidence of hypernatremia $(\geq 150$ $\mathrm{mmol} / \mathrm{L})$ and hyponatremia $(<130)$ was evaluated.

\section{Statistical analyses}

Overall survival was defined as the time from disease onset to death from any cause or the date of the last visit for outpatients without events. Overall survival was estimated using the Kaplan-Meier method, and the survival curves between CDI patients with or without adipsia were compared using the log-rank test. The impacts of adipsia on the morbidity and mortality were evaluated with the multivariate logistic analyses, while those on overall survival were evaluated with Cox regression analyses. These impacts were evaluated after adjusting age at disease onset $(<65 v s \geq 65)$, sex 
(female $v s$ male), anterior pituitary dysfunction (No $v s$ Yes). Additionally, we compared the frequencies of hyponatremia and hypernatremia between CDI patients with or without adipsia until the last follow-up day from the registration day to electronic medical recording systems, using Poisson regression analysis. These frequencies were evaluated after adjusting age at disease onset $(<65 v s \geq 65)$ and sex (female $v s$ male). A two-sided $p<0.05$ was considered to be statistically significant. All the analyses were performed using the SAS (version 9.3; SAS Institute Inc., Cary, NC, USA).

\section{Results}

\section{Etiology}

The etiology in the 149 CDI patients subjected to the analysis of prognosis is shown in Table 1 . The possible causes of CDI were described in $127(85 \%)$ out of the 149 patients. The remaining 22 patients $(15 \%)$ with no obvious trigger for CDI or no abnormality on MRI were considered to be idiopathic.

\section{Serum sodium levels}

Of the 149 patients with CDI subjected to the analysis, 23 patients were judged to be adipsic while the remaining 126 patients had normal sensation of thirst (non-adipsic). The total numbers of serum sodium levels measured were 2130 and 3527 in the adipsic and non-adipsic groups, respectively, and hypernatremia $(\geq 150 \mathrm{mmol} / \mathrm{L})$ was found in 533 measurements
$(25.0 \% ; 150-181 \mathrm{mmol} / \mathrm{L})$ in the adipsic group and in $14(0.4 \% ; 150-156 \mathrm{mmol} / \mathrm{L})$ in the non-adipsic group. The relative risk of hypernatremia in the adipsic group to that in the non-adipsic group was $67.73(p<0.001)$. On the other hand, the incidence of hyponatremia $(<130 \mathrm{mmol} / \mathrm{L})$ was similar between groups (adipsic group: $87 / 2130,4.0 \%, 113-129 \mathrm{mmol} / \mathrm{L}$; non adipsic group: $154 / 3527,4.3 \%, 111-129 \mathrm{mmol} / \mathrm{L}$ ), and the relative risk of hyponatremia in the adipsic group to the non-adipsic group was $0.97(p=0.850)$. Table 2 shows the clinical characteristics of CDI patients with or without adipsia who were subjected to the analysis of the prognosis.

Table 1 Etiology of patients with CDI subjected to analysis of prognosis

\begin{tabular}{lc}
\hline Causes & No. of Patients (\%) \\
\hline idiopathic & $22(15)$ \\
germ cell tumor of CNS & $35(23)$ \\
craniopharyngioma & $32(21)$ \\
neurosurgery & $21(14)$ \\
inflammation & $15(10)$ \\
Rathoke's cleft cyst & $6(4)$ \\
empty sella syndrome & $4(3)$ \\
pituitary adenoma & $4(3)$ \\
malformation & $2(1)$ \\
other & $8(5)$ \\
\hline total & $149(100)$ \\
\hline
\end{tabular}

CNS, central nervous system. "Inflammation" includes lymphocytic infundibulo-neurohypophysitis and IgG4 related diseases.

Table 2 Characteristics of 149 patients with CDI subjected to analyses of prognosis

\begin{tabular}{|c|c|c|c|}
\hline Variables & & $\begin{array}{c}\text { No. of Non-adipsic Patients } \\
(\%)\end{array}$ & $\begin{array}{c}\text { No. of Adipsic Patients } \\
(\%)\end{array}$ \\
\hline Number of patients & & 126 & 23 \\
\hline Age of CDI onset & $\begin{array}{l}<65 \\
\geq 65\end{array}$ & $\begin{array}{l}112(89) \\
14(11)\end{array}$ & $\begin{array}{c}21(91) \\
2(9)\end{array}$ \\
\hline Sex & $\begin{array}{l}\text { Female } \\
\text { Male }\end{array}$ & $\begin{array}{l}55(44) \\
71(56)\end{array}$ & $\begin{array}{l}11(48) \\
12(52)\end{array}$ \\
\hline Anterior pituitary dysfunction & $\begin{array}{l}\text { No } \\
\text { Yes }\end{array}$ & $\begin{array}{l}47(37) \\
79(63)\end{array}$ & $\begin{array}{c}3(13) \\
20(87)\end{array}$ \\
\hline Steroid substitution & $\begin{array}{l}\text { No } \\
\text { Yes }\end{array}$ & $\begin{array}{l}54(43) \\
72(57)\end{array}$ & $\begin{array}{c}4(17) \\
19(83)\end{array}$ \\
\hline T4 substitution & $\begin{array}{l}\text { No } \\
\text { Yes }\end{array}$ & $\begin{array}{l}62(49) \\
64(51)\end{array}$ & $\begin{array}{l}6(26) \\
17(74)\end{array}$ \\
\hline GH substitution & $\begin{array}{l}\text { No } \\
\text { Yes }\end{array}$ & $\begin{array}{l}114(90) \\
12(10)\end{array}$ & $\begin{array}{l}22(96) \\
1(4)\end{array}$ \\
\hline Gonadal hormone substitution & $\begin{array}{l}\text { No } \\
\text { Yes }\end{array}$ & $\begin{array}{c}116(92) \\
10(8)\end{array}$ & $\begin{array}{l}18(78) \\
5(22)\end{array}$ \\
\hline
\end{tabular}


Table 3 Characteristic of patients who died during follow-up

\begin{tabular}{|c|c|c|c|c|c|c|c|}
\hline Patient & $\begin{array}{c}\text { Adipsic/ } \\
\text { Non-adipsic }\end{array}$ & Sex & Age of CDI onset & Age of death & Etiology & $\begin{array}{c}\text { Anterior } \\
\text { dysfunction }\end{array}$ & Cause of death \\
\hline 1 & Adipsic & $\mathrm{F}$ & 25 & 37 & inflammation & yes & $\begin{array}{c}\text { Unclear } \\
\text { (sudden death) }\end{array}$ \\
\hline 2 & Adipsic & M & 12 & 42 & malformation & yes & pneumonia \\
\hline 3 & Adipsic & $\mathrm{F}$ & 10 & 51 & germ cell tumor of CNS & yes & cholecystitis \\
\hline 4 & Adipsic & $\mathrm{F}$ & 77 & 78 & inflammation & no & sepsis \\
\hline 5 & Non-adipsic & $\mathrm{F}$ & 21 & 49 & empty sella syndrome & yes & influenza \\
\hline 6 & Non-adipsic & M & 66 & 78 & Rathoke's cleft cyst & no & renal failure \\
\hline
\end{tabular}

CNS, central nervous system.

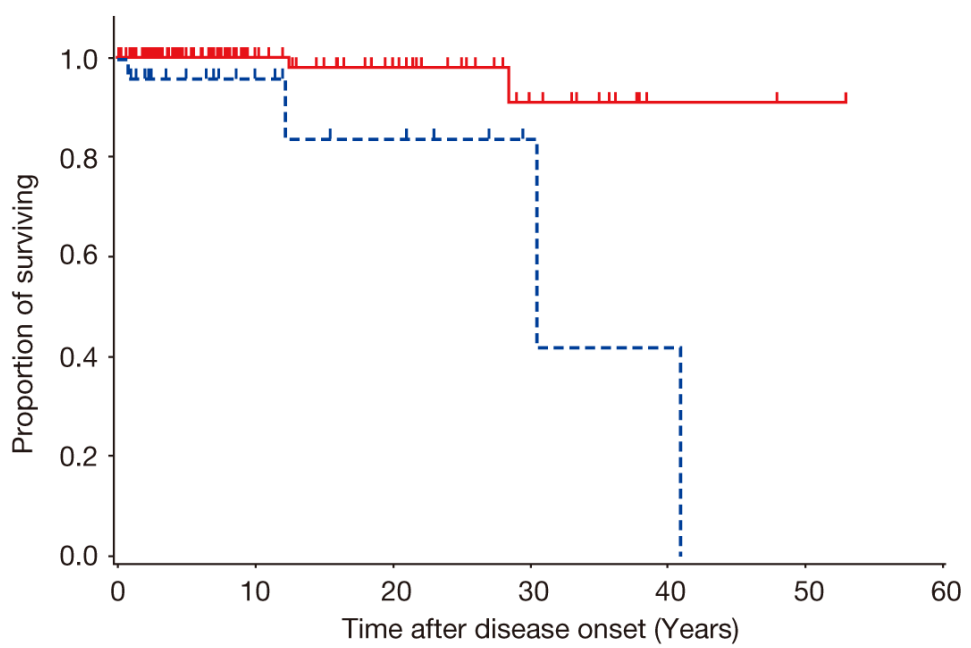

Fig. 1 Kaplan-Meier Curves in CDI Patients With/Without Adipsia

The blue dotted line indicates the survival curve in the adipsic group while the red solid line indicates that in the non-adipsic groups. Short vertical lines indicate censored data points.

\section{Morbidity}

Nine (7\%) of 126 non-adipsic CDI patients experienced serious infections, as did $10(43 \%)$ out of 23 adipsic CDI patients. The multivariate logistic analysis for serious infections showed that the odds ratio $(\mathrm{OR})$ in the adipsic group relative to the nonadipsic group was $8.8(p<0.001)$.

On the other hand, the incidence of respiratory failure was $4 \%(1 / 23)$ and $1 \%(1 / 126)$, and that of thromboembolism was $13 \%(3 / 23)$ and 5\% (6/126) in adipsic and non-adipsic groups, respectively. These differences between groups were not statistically significant.

\section{Mortality}

During the follow-up, 6 patients died; 4 in the adipsic group and 2 in the non-adipsic group. Four patients ( 3 in the adipsic group and 1 in the non-adipsic group) died of infection, and 4 out of the 6 patients were accompanied with anterior pituitary dysfunction. Two patients (No.1 and 5 in Table 3) were found dead at home, and two patients (No.2 and 3 in Table 3) died in other than our 3 hospitals, because they were transferred there by ambulance. The characteristics of these 6 patients were shown in Table 3 .

Fig. 1 shows the Kaplan-Meier curves in the CDI patients with/without adipsia. The difference of the two survival curves was statistically significant ( $p=0.015$ ). Table 4 shows the results of multivariate logistic and Cox regression analyses. The risk of death in CDI patients with adipsia was significantly higher than in those without adipsia (OR, 9.53, 95\% CI, 1.85 to 49.08, $p=0.007$ ). The overall survival in CDI patients with adipsia was significantly shorter than in those without adipsia (HR, 
Table 4 Results of Multivariate Logistic and Cox Regression analyses

\begin{tabular}{|c|c|c|c|c|c|c|c|c|c|}
\hline \multirow{2}{*}{ Variables } & & \multicolumn{4}{|c|}{ Logistic regression analysis } & \multicolumn{4}{|c|}{ Cox regression analysis } \\
\hline & & OR & & CI & $p$ & HR & & $\% \mathrm{CI}$ & $p$ \\
\hline Adipsia & $\begin{array}{l}\text { No } \\
\text { Yes }\end{array}$ & $\begin{array}{c}1 \\
9.53\end{array}$ & 1.85 & 49.08 & 0.007 & $\begin{array}{c}1 \\
10.46\end{array}$ & 1.03 & 105.99 & 0.047 \\
\hline Age & $\begin{array}{l}<65 \\
\geq 65\end{array}$ & $\begin{array}{c}1 \\
6.50\end{array}$ & 0.99 & 42.55 & 0.051 & $\begin{array}{c}1 \\
137.88\end{array}$ & 6.17 & 3080.33 & 0.002 \\
\hline Sex & $\begin{array}{c}\text { Female } \\
\text { Male }\end{array}$ & $\begin{array}{c}1 \\
0.50\end{array}$ & 0.10 & 2.47 & 0.398 & $\begin{array}{c}1 \\
0.52\end{array}$ & 0.06 & 4.25 & 0.544 \\
\hline $\begin{array}{l}\text { Anterior pituitary } \\
\text { dysfunction }\end{array}$ & $\begin{array}{l}\text { No } \\
\text { Yes }\end{array}$ & $\begin{array}{c}1 \\
1.57\end{array}$ & 0.20 & 11.98 & 0.666 & $\begin{array}{c}1 \\
0.83\end{array}$ & 0.07 & 9.61 & 0.880 \\
\hline
\end{tabular}

OR, odds ratio; HR, hazard ratio; $\mathrm{CI}$, confidence interval.

$10.46,95 \% \mathrm{CI}, 1.03$ to $105.99, p=0.047)$. The anterior pituitary dysfunction did not impact the prognosis in the two analyses (OR, 1.57, 95\% CI, 0.20 to $11.98, p=0.666$; HR, $0.83,95 \% \mathrm{CI}, 0.07$ to $9.61, p=0.880$ ).

\section{Discussion}

The prevalence of CDI is reported to be 1:25000 [7]. Because of its rarity, the numbers of CDI patients in previous studies were less than 100 [4-6], and the investigation of CDI prognosis has been difficult. In the present study, using databases of 3 hospital electronic medical recording systems, we evaluated 149 patients with CDI for the prognosis. The ages of CDI onset ranged from 0 to 78 year, and the median age was 36 years. The results in this study could thus represent the prognosis of CDI patients at all ages. While the number of the CDI patients enrolled in this study is still small, our data clearly showed that the risk of death in adipsic CDI patients was significantly higher than that in the non-adipsic CDI patients.

DDAVP is an AVP analogue which has been used in the treatment of CDI. As deficiency or excess of DDAVP could potentially lead to hypernatremia or hyponatremia, the individual dose titration of DDAVP is required. The appropriate amount of daily water intake should also be established in adipsic CDI patients $[2,7]$. Most adipsic CDI patients in this study were encouraged to measure body weight every day and to determine the amount of daily water intake based on the body weight, with a fixed amount of DDAVP. However, it is not easy to maintain water balance in adipsic CDI patients. Indeed, the present study revealed that the incidence of hypernatremia in the adipsic CDI patients (25\%) was significantly higher than that in non-adipsic CDI patients $(0.4 \%)$, suggesting that adipsic CDI patients are often subjected to dehydration.

Systemic dehydration has been implicated in a number of human diseases [12] and could affect immune functions as well [13]. In this regard, it is noteworthy that the incidence of serious infections was significantly higher in the adipsic group compared to the non-adipsic group, and that 3 patients in the adipsic group died of infection in this study. Our data thus suggest that the adipsic CDI patients, who are chronically dehydrated, are susceptible to serious infections, and underscore the importance of controlling water balance, in particular during illness in these patients.

While our study did not show significant differences in the incidence of morbidity other than infections, it is reported that patients with adipsic CDI often have respiratory failure and thromboembolic complications $[9,14]$. Thus, physicians should be aware of the high rates of mortality and morbidity in patients with adipsic CDI. Previous investigators have reported that the prognosis of patients with anterior pituitary dysfunction is not good $[15,16]$. In fact, 4 out of 6 patients who died during follow-up in our study were accompanied by anterior pituitary dysfunction. The statistical analysis, however, did not show any significant effects of anterior dysfunction on the prognosis. This is probably due to the limited number of patients in this study, and further points up the significance of adipsia as a determinant of prognosis in CDI patients.

In conclusion, our study demonstrated that the risk of death in adipsic CDI patients is significantly higher than that in non-adipsic CDI patients. As the incidence of serious infections was significantly higher in the adipsic CDI patients compared to that in non-adipsic CDI patients, and the causes of death in 3 of the 4 
adipsic CDI patients were infections, it is suggested that water balance should be monitored and well controlled in these patients, particularly during illness.

\section{Acknowledgements}

We thank Drs. Ryo Horibe, Miho Ushida, Naoko
Iwata, Shingo Umemura, Masatoshi Murase, Chinatsu Matsunaga, and Junko Nagai for their special assistance.

\section{Disclosures}

The authors have no conflicts of interest.

\section{References}

1. Robertson GL (1995) Posterior pituitary. In Felig P, Baxter J, Frohman L, eds. Endocrinology and metabolism. New York: McGraw-Hill; 385-432.

2. Robinson AG, Verbalis JG (2008) Posterior Pituitary. In Kronenberg HM, Melmed S, Polonsky KS, Larsen PR, eds. Williams textbook of endocrinology. PA: Saunders Elsevier; 263-295.

3. Baylis PH, Thompson CJ (1988) Osmoregulation of vasopressin secretion and thirst in health and disease. Clin Endocrinol (Oxf) 29: 549-576.

4. Maghnie M, Cosi G, Genovese E, Manca-Bitti ML, Cohen A, Zecca S, Tinelli C, Gallucci M, Bernasconi S, Boscherini B, Severi F, Aricò M (2000) Central diabetes insipidus in children and young adults. $N$ Engl J Med 343: 998-1007.

5. Bajpai A, Kabra M, Menon PS (2008) Central diabetes insipidus: clinical profile and factors indicating organic etiology in children. Indian Pediatr 45: 463-468.

6. Catli G, Abaci A, Demir K, Ulusoy E, Altincik A, Buyukgebiz A, Bober E (2012) Clinical profile and etiologies of children with central diabetes insipidus: a single-center experience from Turkey. J Pediatr Endocrinol Metab 25: 499-502.

7. Di Iorgi N, Napoli F, Allegri AE, Olivieri I, Bertelli E, Gallizia A, Rossi A, Maghnie M (2012) Diabetes insipidus--diagnosis and management. Horm Res Paediatr 77: 69-84.

8. Fenske W, Allolio B (2012) Clinical review: Current state and future perspectives in the diagnosis of diabetes insipidus: a clinical review. J Clin Endocrinol Metab 97: $3426-3437$
9. Crowley RK, Sherlock M, Agha A, Smith D, Thompson CJ (2007) Clinical insights into adipsic diabetes insipidus: a large case series. Clin Endocrinol (Oxf) 66: 475-482.

10. Mandal AK, Saklayen MG, Hillman NM, Markert RJ. (1997) Predictive factors for high mortality in hypernatremic patients. Am J Emerg Med 15: 130-132.

11. Mahowald JM, Himmelstein DU (1981) Hypernatremia in the elderly: relation to infection and mortality. $\mathrm{J} \mathrm{Am}$ Geriatr Soc 29: 177-180.

12. Brocker C, Thompson DC, Vasiliou V (2012) The role of hyperosmotic stress in inflammation and disease. Biomol Concepts 3: 345-364.

13. Jang TR, Kao MF, Chen CH, Hsieh KC, Lai WY, Chen YY (2011) Alleviating effects of dehydration under no hyperthermia on the immunomodulatory response to the polysaccharide fraction from fu-ling (Poria cocos) in male collegiate wrestlers. Chin Med $J$ (Engl)124: 530-536.

14. Hannon MJ, Finucane FM, Sherlock M, Agha A, Thompson CJ (2012) Disorders of water homeostasis in neurosurgical patients. $J$ Clin Endocrinol Metab 97:1423-1433.

15. Rosén T, Bengtsson BA (1990) Premature mortality due to cardiovascular disease in hypopituitarism. Lancet 336: $285-288$.

16. Tomlinson JW, Holden N, Hills RK, Wheatley K, Clayton RN, Bates AS, Sheppard MC, Stewart PM (2001) Association between premature mortality and hypopituitarism. West Midlands Prospective Hypopituitary Study Group. Lancet 357: 425-431. 